\title{
Preparation of $\mathrm{LDO} @ \mathrm{TiO}_{2}$ core-shell nanosheets for enhanced photocatalytic degradation of organic pollutions
}

\author{
Can Wang ${ }^{\mathrm{a}}$, Ruikang Zhang ${ }^{\mathrm{a}, *}$, Yucong Miao ${ }^{\mathrm{b}}$, Qihui Xue ${ }^{\mathrm{a}}$, Borong $\mathrm{Yu}^{\mathrm{a}}$, Yuanzhe Gao ${ }^{\mathrm{a}}$, Zhan-gang \\ $\operatorname{Han}^{\mathrm{a}}$, Mingfei Shao ${ }^{\mathrm{b}}$ \\ ${ }^{a}$ Hebei Key Laboratory of Organic Functional Molecules, College of Chemistry and Materials \\ Science, Hebei Normal University, Shijiazhuang, Hebei 050024, China. \\ ${ }^{b}$ State Key Laboratory of Chemical Resource Engineering, Beijing University of Chemical

$$
\text { Technology, Beijing 100029, China }
$$$$
\text { E-mail: zhangruikang@hebtu.edu.cn }
$$

\begin{abstract}
TiO}_{2}$-based nanosheets materials with core-shell structure are expected to be one of the promising photocatalysts to degradation of organic pollutions. However, it is a challenge to synthesis of $\mathrm{TiO}_{2}$ shell on functional core materials by desired nucleation and growth process. Layered double hydroxides (LDHs) are considered as ideal platforms to in-situ grow $\mathrm{TiO}_{2}$ and further serve as additional components to construct heterojunction to improve the separation of photo-generated charge carriers. In this work, we report the design and fabrication of anatase $\mathrm{TiO}_{2}$ coated ZnAl-layered double oxide $\left(\mathrm{LDO} @ \mathrm{TiO}_{2}\right)$ nanosheets, which involves the in-situ growth of $\mathrm{TiO}_{2}$ on ZnAl-LDH followed by a subsequent calcination treatment. The resulting $\mathrm{LDO} @ \mathrm{TiO}_{2}$ photocatalyst gives typical core-shell nanosheets morphology with mesoporous structure, which exhibiting excellent photodegradation and mineralization efficiency for organic pollutions.
\end{abstract}

Keywords: LDO@ $\mathrm{TiO}_{2}$ nanosheets; core-shell; LDHs; photocatalysts; photodegradation

\section{Introduction}

Photodegradation is a promising technology to remove the organic pollutants from wastewater, which can directly utilize solar energy to mineralize pollutants (e.g., dyes, antibiotics and aromatic 
compounds) into $\mathrm{CO}_{2}$ and $\mathrm{H}_{2} \mathrm{O}$ [1-5]. Photocatalysts play a key role in the photodegradation process, and many semiconductors (e.g., $\mathrm{TiO}_{2}$ [6], $\alpha-\mathrm{Fe}_{2} \mathrm{O}_{3}$ [7], $\mathrm{WO}_{3}[8]$ and $\mathrm{BiVO}_{4}$ [9]) have been studied as photocatalyst for photodegradation. Because of the excellent stability and catalytic activity, $\mathrm{TiO}_{2}$ is expected to be one of the promising photocatalysts. In recent years, nanosheets [10], nanorods [11], nanotubes [12] and microspheres [13] $\mathrm{TiO}_{2}$ materials with control of crystallinity and exposed facets have been reported. The nanostructured $\mathrm{TiO}_{2}$ materials present efficient active sites and large surface area, resulting in enhanced photocatalytic degradation performance [14-16]. However, the inherent low electron mobility and short hole diffusion length of $\mathrm{TiO}_{2}$ bring about intense charge recombination, and hinders their photocatalytic activity.

The photodegradation process involves the generation, separation of charge carriers and the following redox reactions of pollutants [17-21]. To enhance the photocatalytic degradation performance of $\mathrm{TiO}_{2}$, it is an efficient method to fabricate $\mathrm{TiO}_{2}$-based composite photocatalysts. For example, building $\mathrm{TiO}_{2} / \mathrm{NiO}$ heterojunction can enhance the separation of photogenerated electron-hole pairs [22]; introducing graphene oxide to $\mathrm{TiO}_{2}$ facilitates the generation of $\mathrm{O}_{2}{ }^{--}$and $\mathrm{HO}^{\bullet}$ radicals, thereby improving the photocatalytic activities towards organic pollutions [23]. Among the composite photocatalysts, core-shell structured materials attract lots of attention as they usually possess highly distinctive physical and chemical properties in the integrated system. For instance, $\mathrm{TiO}_{2} @ \mathrm{Bi}_{2} \mathrm{~W}_{\mathrm{x}} \mathrm{Mo}_{1-\mathrm{x}} \mathrm{O}_{6}$ core-shell nanofibers possess boosting visible light absorption and reduced charge recombination rate, exhibiting good photocatalytic activities towards tetracycline hydrochloride [24]; $\mathrm{CoTiO}_{3}$ coated nanosheets-assembled $\mathrm{TiO}_{2}$ nanospheres can promote the photodegradation of antibiotics due to the enhanced charge separation efficiency and mass transfer [25]; However, the reported $\mathrm{TiO}_{2}$-based core-shell photocatalysts mostly are $\mathrm{TiO}_{2}$ as shell material, which is disadvantage of the exposure of catalytic activity sites in $\mathrm{TiO}_{2}$. In addition, nanosheet photocatalysts are recognized as an ideal structure to reduce the charge migration distance and further suppress the charge recombination [26-28]. Therefore, it is attractive to fabricate $\mathrm{TiO}_{2}$-based 
core-shell nanosheets materials, especially $\mathrm{TiO}_{2}$ as shell-materials with enhanced photocatalytic performance. However, it is a challenge to synthesis of $\mathrm{TiO}_{2}$ shell on functional core materials by desired nucleation and growth process.

Layered double hydroxides (LDHs) are typical two-dimensional cationic clays with the general formula $\left[\mathrm{M}^{\mathrm{II}}{ }_{1-x} \mathrm{M}^{\mathrm{III}}{ }_{x}(\mathrm{OH})_{2}\right]^{\mathrm{x}+} \cdot\left(\mathrm{A}^{\mathrm{n}-}{ }_{x / n}\right) \cdot \mathrm{mH}_{2} \mathrm{O}$, where $\mathrm{M}^{\mathrm{II}}$ and $\mathrm{M}^{\mathrm{III}}$ are bivalent and trivalent metal cations, $\mathrm{A}^{\mathrm{n}-}$ are interlayer anions $\left(\mathrm{CO}_{3}{ }^{2-}, \mathrm{Cl}^{-}, \mathrm{SO}_{4}{ }^{2-}\right.$ etc.). The structure of $\mathrm{M}^{\mathrm{II}} \mathrm{M}^{\mathrm{III}}-\mathrm{LDHs}$ is orderly formed by positive charged metal layer $\left[\mathrm{M}^{\mathrm{II}}{ }_{1-x} \mathrm{M}^{\mathrm{III}}{ }_{x}(\mathrm{OH})_{2}\right]$ and interlayer anions for charge compensation [29-31]. The unsaturated coordination state of LDHs surface is advantage of the nucleation and growth of extrinsic components [32-34]. The hydroxyl group in metal layer can provide reaction sites for the hydrolysis of titanium precursor. After calcination of LDHs, the obtained layer double oxides (LDOs) are composite of mixed metal oxides and can be considered as a new type of semiconductor materials. For example, ZnAl-LDO and NiTi-LDO has been reported as excellent photocatalysts $[35,36]$. Therefore, LDHs nanosheets are promising platforms to in-situ grow $\mathrm{TiO}_{2}$ and further serve as additional components to construct heterojunction or other functional materials to improve the separation of photo-generated charge carriers.

Herein, we report the design and fabrication of anatase $\mathrm{TiO}_{2}$ coated $\mathrm{ZnAl}-\mathrm{LDO}\left(\mathrm{LDO} @ \mathrm{TiO}_{2}\right)$ nanosheets, which involves the in-situ growth of $\mathrm{TiO}_{2}$ on $\mathrm{ZnAl-LDH}$ followed by a subsequent calcination treatment. The resulting $\mathrm{LDO} @ \mathrm{TiO}_{2}$ photocatalyst gives typical core-shell nanosheets morphology with mesoporous structure. The $\mathrm{ZnAl-LDO}$ core material is consisting of zincite $\mathrm{ZnO}$ and amorphous $\mathrm{Al}_{2} \mathrm{O}_{3}$, and $\mathrm{TiO}_{2}$ shell material is anatase $\mathrm{TiO}_{2}$. The $\mathrm{ZnAl}-\mathrm{LDO} / \mathrm{TiO}_{2}$ heterojunction in the core/shell interface facilitate the charge separation and further promote the photodegradation of dyes. Consequently, $\mathrm{LDO} @ \mathrm{TiO}_{2}$ photocatalysts exhibits excellent photodegradation and mineralization efficiency for organic dyes. This work provides an elaborate strategy for the preparation of $\mathrm{TiO}_{2}$ nanosheets heterojunction materials using LDHs as platform, which has potential applications in the field of photocatalysts. 


\section{Experiments}

\subsection{Materials}

$\mathrm{ZnCl}_{2}, \mathrm{Al}\left(\mathrm{NO}_{3}\right)_{3} \cdot 9 \mathrm{H}_{2} \mathrm{O}$, tetrabutyl titanate $\left[\mathrm{Ti}(\mathrm{OBu})_{4}\right]$, urea, ethanol, 5,5-dimethyl-1-pyrroline N-oxidewere (DMPO), $\mathrm{Na}_{2} \mathrm{SO}_{4}$, rutile $\mathrm{TiO}_{2}$ were purchased from Shanghai Aladdin Bio-Chem Technology Co., LTD. P25 $\mathrm{TiO}_{2}$ was purchased from Aeroxide Degussa, Germany. The water used in all experiments was purified through a Millipore system.

\subsection{Preparation of ZnAl-LDH and ZnAl-LDO}

ZnAl-LDH was prepared in a three-neck flask equipped with a reflux condenser under a nitrogen flow [37]. Typically, $\mathrm{ZnCl}_{2}(4 \mathrm{mmol}), \mathrm{Al}\left(\mathrm{NO}_{3}\right)_{3} \cdot 9 \mathrm{H}_{2} \mathrm{O}(2 \mathrm{mmol})$ and urea $(14 \mathrm{mmol})$ were dissolved in $400 \mathrm{~mL}$ of deionized water. The solution was then heated at $97{ }^{\circ} \mathrm{C}$ under refluxing and continuous stirring for $24 \mathrm{~h}$. The resulting product was washed with ethanol for several times, and finally dried in air.

The as-prepared ZnAl-LDH was placed in a ceramic boat and transferred into a muffle furnace. ZnAl-LDO- $T\left(T=200,400,600,800{ }^{\circ} \mathrm{C}\right)$ were obtained with calcination temperature at 200,400 , $600,800{ }^{\circ} \mathrm{C}$, respectively, in the air for $2 \mathrm{~h}$ with a heating rate of $5^{\circ} \mathrm{C} \min ^{-1}$. ZnAl-LDO-600 was abbreviated as ZnAl-LDO.

\subsection{Preparation of $\mathrm{LDH} @ \mathrm{TiO}_{2}$ and $\mathrm{LDO} @ \mathrm{TiO}_{2}$}

LDH@ $\mathrm{TiO}_{2}$ was synthesized by solvothermal method. Typically, $1.2 \mathrm{~g} \mathrm{ZnAl}-\mathrm{LDH}$ was dispersed into $25 \mathrm{~mL} 99.5 \%$ ethanol solution, and then $0.4 \mathrm{~mL} \mathrm{Ti}(\mathrm{OBu})_{4}$ was added into the above solution under magnetic stirring at room temperature. Then, the solutions were aged in a $50 \mathrm{~mL}$ teflon-lined stainless steel autoclave at $100{ }^{\circ} \mathrm{C}$ for $12 \mathrm{~h}$. After cooling down to room temperature, the LDH@ $\mathrm{TiO}_{2}$ samples were washed several times with deionized water, and finally dried in air. For preparation of $\mathrm{LDH} @ \mathrm{TiO}_{2}-\mathrm{L}$ and $\mathrm{LDH}_{0} \mathrm{TiO}_{2}-\mathrm{H}, 0.2 \mathrm{~mL}$ and $0.6 \mathrm{~mL} \mathrm{Ti}(\mathrm{OBu})_{4}$ were added into the ethanol solution, respectively. The other processes were performed by the same method of LDH@ $\mathrm{TiO}_{2}$. 


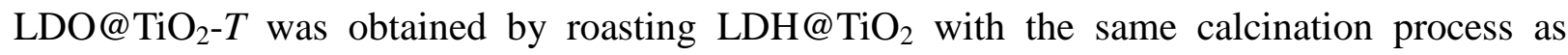
ZnAl-LDO. LDO@ $\mathrm{TiO}_{2}-600$ was abbreviated as LDO@ $\mathrm{TiO}_{2}$.

\subsection{Characterization}

The morphology was investigated using a scanning electron microscopy (SEM; Hitachi, S-4800). X-ray diffraction (XRD) patterns were collected on a Rigaku XRD-6000 diffractometer using $\mathrm{Cu} \mathrm{K} \alpha$ radiation with a scan step of $10^{\circ} \mathrm{min}^{-1}$. Thermogravimetric (TG) curves were collected on a STA449F3/TENSOR27 TG/DTA instrument under $\mathrm{N}_{2}$ atmosphere with a heating rate of $10{ }^{\circ} \mathrm{C}$ $\min ^{-1}$. X-ray photoelectron spectra (XPS) were recorded on a Thermo VG Escalab 250 with Al $\mathrm{K \alpha}$ $\mathrm{X}$-rays as the excitation source. Transmission electron microscopy (TEM) images were collected on recorded using a Philips Tecnai 20 and JEOL JEM-2010 high-resolution transmission electron microscopes. X-ray spectrometry (EDS) elemental mapping were operated with a probe focused to $0.2 \mathrm{~nm}$. The specific surface area, pore volume and size analysis were performed by Brunauer-Emmett-Teller and Barrett-Joyner-Halenda method, respectively, using a Kubo-X1000 analyzer. Solid UV-Vis diffuse reflection spectra and UV-Vis adsorption spectra was characterized using an Agilent Cary 60 spectrophotometer. Electron paramagnetic resonance (EPR) dates were collected on a Bruker E500 EPR spectrometer at room temperature with a $300 \mathrm{~W}$ Xe lamp as illuminant. Total organic carbon (TOC) was determined using TOC-L (Shimadzu, Japan).

\subsection{Photocatalytic degradation experiments}

Methylene blue (MB, cationic dye) and acid orange (AO, anion dye) were used as representative organic pollutions to investigated the photocatalytic activity of prepared samples. The illumination source was a $150 \mathrm{~W}$ Xe lamp under AM 1.5G simulated solar irradiation with a power density of $100 \mathrm{~mW} \mathrm{~cm}{ }^{-2}$. The degradation experiment was carried out on a home-made $250 \mathrm{~mL}$ glass reactor. Photocatalyst $(50 \mathrm{mg})$ was firstly dispersed to $100 \mathrm{~mL}$ aqueous solution $\mathrm{MB}\left(10 \mathrm{mg} \mathrm{L}^{-1}\right)$ or AO $\left(25 \mathrm{mg} \mathrm{L}^{-1}\right)$. The suspension was magnetically stirred in the dark for $40 \mathrm{~min}$ to ensure adsorption-desorption equilibrium. Then, irradiation was carried out, and this point was recorded as 
the initiation time. At certain time intervals, $4 \mathrm{~mL}$ of the suspension was removed and filtered using a $0.22 \mu \mathrm{m}$ filter for analysis. The concentration of $\mathrm{MB}$ (or $\mathrm{AO}$ ) was analyzed by measuring the absorbance at maximum wavelength of $664 \mathrm{~nm}(484 \mathrm{~nm})$ using a UV-vis spectrophotometer. The degradation or TOC removal ratios were calculated according to the equation: $\left(C_{0}-C_{\mathrm{t}}\right) / C_{0} \times 100 \%$ or $\left(T O C_{0}-T O C_{\mathrm{t}}\right) / T O C_{0} \times 100 \%$, where $C_{0}$ and $T O C_{0}$ are the initial concentrations of dyes; $C_{\mathrm{t}}$ and $T O C_{\mathrm{t}}$ are the concentrations of dyes at reaction time.

2.6 Photoelectrochemical measurements

A homogeneous suspension was prepared by dispersing $10 \mathrm{mg}$ as-prepared photocatalyst in 2 $\mathrm{mL}$ ethanol. Then, $50 \mu \mathrm{L}$ of the suspension was dip-coated on the fluorine-doped tin oxide $(2 \mathrm{~cm} \times 2$ $\mathrm{cm}$ ) followed by drying in a vacuum oven at $60{ }^{\circ} \mathrm{C}$ for $2 \mathrm{~h}$. Photocurrent measurements were conducted on an electrochemical workstation (CHI 660e, $\mathrm{CH}$ Instruments Inc., Shanghai) in $0.1 \mathrm{M}$ $\mathrm{Na}_{2} \mathrm{SO}_{4}$ aqueous solution with a conventional three-electrode cell. The illumination source was a 150 W Xe lamp under AM 1.5G simulated solar irradiation with a power density of $100 \mathrm{~mW} \mathrm{~cm}^{-2}$. The as-obtained ZnAl-LDO and $\mathrm{LDO} @ \mathrm{TiO}_{2}$ as working electrode were immersed in the electrolyte. The Pt wire as counter electrode, saturated calomel electrode (SCE) as the reference electrode are installed in a quartz cell.

\section{Results and discussion}

\subsection{Materials preparation and characterization}

The preparation process of $\mathrm{TiO}_{2}$ coated $\mathrm{ZnAl}-\mathrm{LDO}\left(\mathrm{LDO} @ \mathrm{TiO}_{2}\right)$ core-shell nanosheets is illustrated in Figure 1a, which involves the in-situ growth of $\mathrm{TiO}_{2}$ on $\mathrm{ZnAl-LDH}$ nanosheets followed by a subsequent calcination process. ZnAl-LDH nanosheets were firstly prepared by a reported hydrothermal process, and it presents typical hexagonal platelets with thickness of 100-200 nm and diameter of $2-5 \mu \mathrm{m}$ (Figure $1 \mathrm{~b}$ ). Then, amorphous $\mathrm{TiO}_{2}$ was in-situ growing on the surface of ZnAl-LDH nanosheets by the controllable hydrolysis of tetrabutyl titanate $\left[\mathrm{Ti}(\mathrm{OBu})_{4}\right]$. The thickness of $\mathrm{TiO}_{2}$ coated on $\mathrm{ZnAl}-\mathrm{LDH}$ nanosheets $\left(\mathrm{LDH} @ \mathrm{TiO}_{2}\right)$ increase to $150-250 \mathrm{~nm}$ after the growth of 
$\mathrm{TiO}_{2}$ shell (Figure 1c). Finally, $\mathrm{LDO} @ \mathrm{TiO}_{2}$ core-shell nanosheets were obtained after the calcination process at $600{ }^{\circ} \mathrm{C}$, which inherits the morphology of $\mathrm{LDH}_{0} \mathrm{TiO}_{2}$ (Figure 1d). In addition, ZnAl-LDO sample was prepared to give a comparison study by calcining ZnAl-LDH with the same conditions, which also shows lamellar morphology (Figure S1).

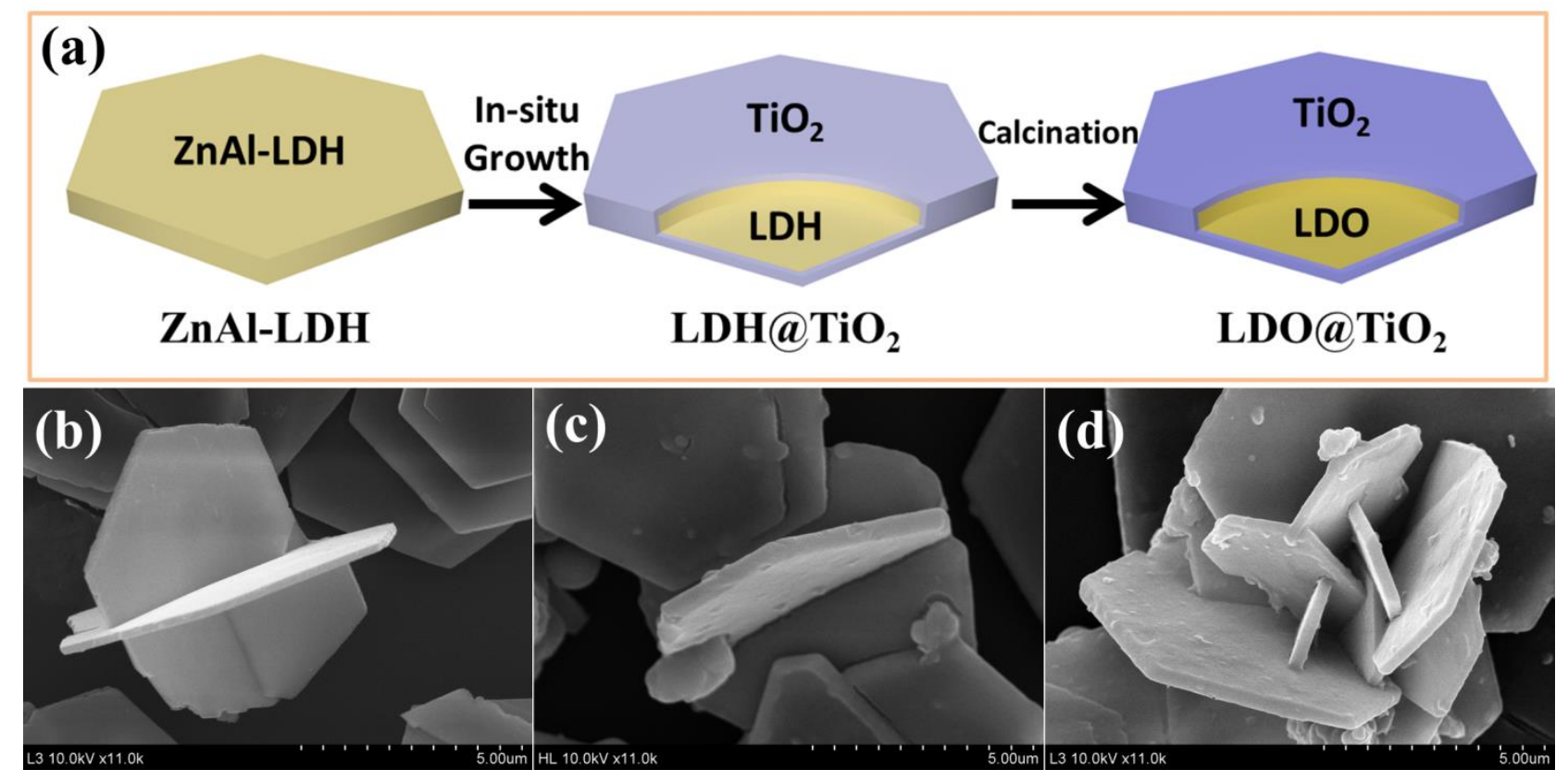

Figure 1. (a) Schematic illustration for the preparation process of $\mathrm{LDO} @ \mathrm{TiO}_{2}$. SEM images of (b) ZnAl-LDH, (c)

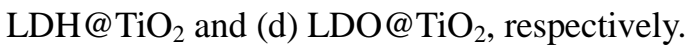

The phase structure of $\mathrm{ZnAl-LDH,} \mathrm{LDH@} \mathrm{TiO}_{2}$ and their derived calcined samples ZnAl-LDO, LDO@ $\mathrm{TiO}_{2}$ were investigated by X-ray diffraction (XRD) method. As shown in Figure 2a, ZnAl-LDH displays the typical (003), (006), (009) reflections at $12.2^{\circ}, 24.3^{\circ}, 36.0^{\circ}$, respectively. No added reflection is observed in $\mathrm{LDH}_{\mathrm{T}} \mathrm{TiO}_{2}$, indicating the amorphous phase of $\mathrm{TiO}_{2}$ shell. $\mathrm{ZnAl-LDO}$ shows a series of new reflections at $31.8^{\circ}, 34.4^{\circ}$ and $36.3^{\circ}$ corresponding to (100), (002) and (101) planes of zincite $\mathrm{ZnO}$ (PDF\#36-1451). The absence of $\mathrm{Al}_{2} \mathrm{O}_{3}$ reflections demonstrates that $\mathrm{ZnAl}-\mathrm{LDO}$ is consisting of zincite $\mathrm{ZnO}$ and amorphous $\mathrm{Al}_{2} \mathrm{O}_{3}$, which is consistent with previous report [38]. It is worth mention that the amorphous $\mathrm{Al}_{2} \mathrm{O}_{3}$ can enhance the structure stability of LDOs nanosheets. For $\mathrm{LDO} @ \mathrm{TiO}_{2}$, the (101) plane of anatase $\mathrm{TiO}_{2}$ at $25.3^{\circ}(\mathrm{PDF} 21-1272)$ and the reflections of $\mathrm{ZnAl-LDO}$ both can be observed in the XRD pattern. The superimposition of $\mathrm{ZnO}$ and 
$\mathrm{TiO}_{2}$ phases in $\mathrm{LDO} @ \mathrm{TiO}_{2}$ demonstrate the effective combination of $\mathrm{ZnAl}-\mathrm{LDO}$ and anatase $\mathrm{TiO}_{2}$. Furthermore, the effect of calcination temperature on the structural evolution phase conversion of ZnAl-LDH and LDH@ $\mathrm{TiO}_{2}$ was investigated. Thermogravimetric (TG) curves show that ZnAl-LDH presents three weight loss stages (Figure $2 \mathrm{~b}$ ). The first step $\left(20-220{ }^{\circ} \mathrm{C}\right)$ has a $\sim 13.5 \%$ weight loss corresponds to the removal of crystal water and interlayer water. The second weight loss is $\sim 13.6 \%$ $\left(220-350{ }^{\circ} \mathrm{C}\right)$, which can be ascribed to the dehydroxylation of the hydroxide layers and decomposition of the interlayer anions. The third step (weight loss $\sim 4.2 \%$ at $350-850{ }^{\circ} \mathrm{C}$ ) is

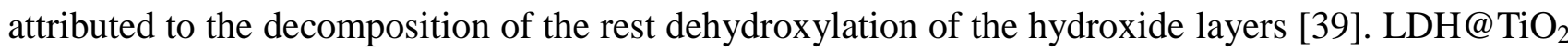
also displays three weight loss stages as $\mathrm{ZnAl-LDH}$. Because phase conversion process of $\mathrm{TiO}_{2}$ has less weight loss during the heating process [40], the three steps weight loss of $\mathrm{LDH}_{\mathrm{T}} \mathrm{TiO}_{2}$ is only $\sim 12.3 \%\left(20-220{ }^{\circ} \mathrm{C}\right), \sim 8.5 \%\left(220-350{ }^{\circ} \mathrm{C}\right)$ and $\sim 2.6 \%\left(350-850{ }^{\circ} \mathrm{C}\right)$, respectively. The XRD patterns of $\mathrm{LDO} @ \mathrm{TiO}_{2}$ sample at four calcination temperatures (denoted as $\mathrm{LDO} @ \mathrm{TiO}_{2}-T$; $T$ is the temperature) confirms the results of TG. As shown in Figure 2c, LDO@ TiO 2 -200 displays week reflections of $\mathrm{LDH}$, indicating the reserve of lamellar structure of $\mathrm{LDH}$. The (003) reflection of LDH at $12.2^{\circ}$ disappears accompanied by the appearance of (002) facet of zincite $\mathrm{ZnO}$ at $34.4^{\circ}$ in LDO@ $\mathrm{TiO}_{2}-400$, indicating the dehydroxylation of the hydroxide layers. The reflections of $\mathrm{ZnO}$ and

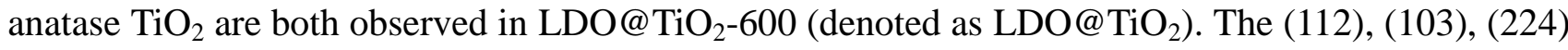
planes of $\mathrm{Zn}_{2} \mathrm{TiO}_{4}(\mathrm{PDF} \# 19-1483)$ at $29.9^{\circ}, 35.2^{\circ}, 62.1^{\circ}$ and (220) (311) planes of $\mathrm{ZnAl}_{2} \mathrm{O}_{4}$ (PDF\#05-0669) at $31.2^{\circ}, 36.8^{\circ}$ are observed in $\mathrm{LDO} @ \mathrm{TiO}_{2}-800$, suggesting that $\mathrm{TiO}_{2}, \mathrm{ZnO}$ and $\mathrm{Al}_{2} \mathrm{O}_{3}$ convert to the cubic spinel phase $\left(\mathrm{Zn}_{2} \mathrm{TiO}_{4}\right.$ and $\left.\mathrm{ZnAl}_{2} \mathrm{O}_{4}\right)$. ZnAl-LDO-T samples show similar phases compared with the corresponding LDO@ $\mathrm{TiO}_{2}-T$ sample but without the phases containing $\mathrm{Ti}$ element (Figure S2). For example, only (220) (311) planes of $\mathrm{ZnAl}_{2} \mathrm{O}_{4}$ are observed in ZnAl-LDO-800. These results indicate that ZnAl-LDO can maintain structure stability in a wide calcination temperature. 

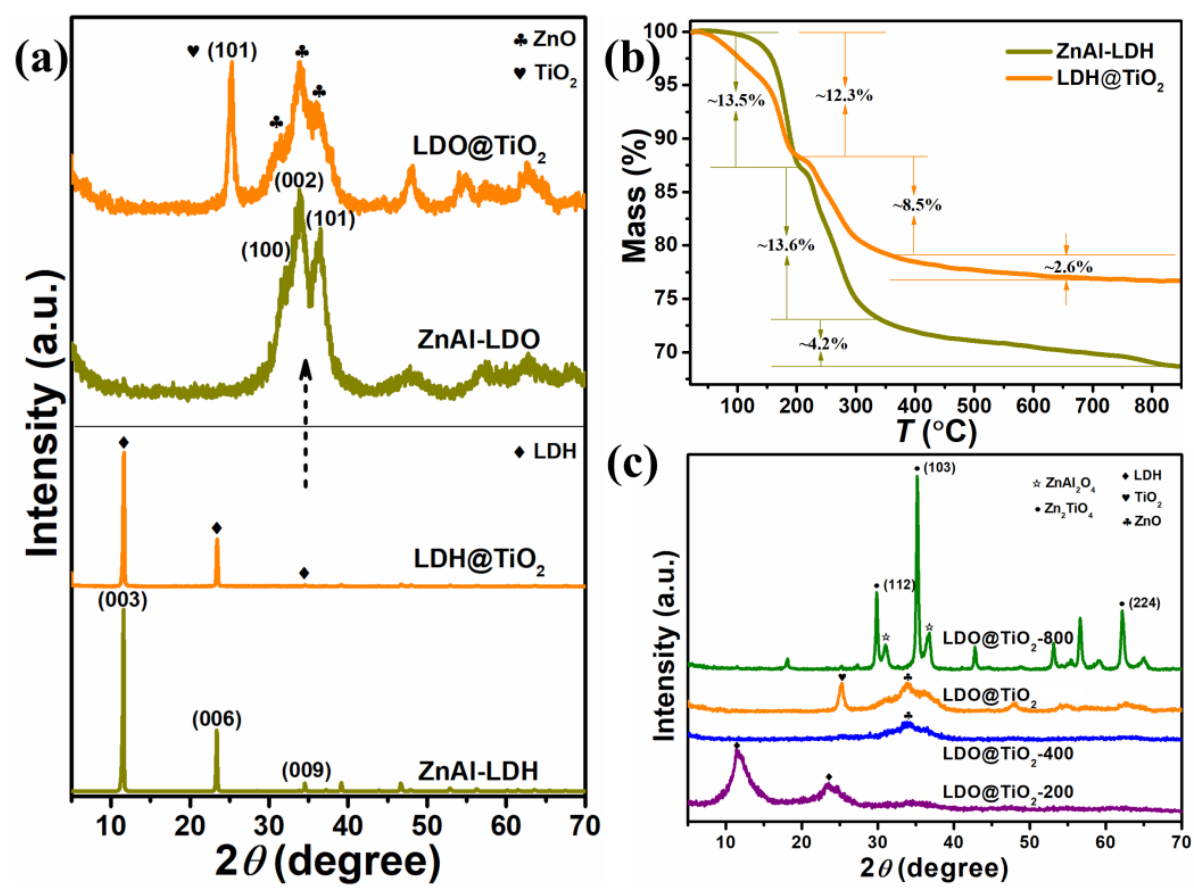

Figure 2. (a) XRD patterns of $\mathrm{ZnAl}-\mathrm{LDH}, \mathrm{LDH} @ \mathrm{TiO}_{2}, \mathrm{ZnAl}-\mathrm{LDO}$ and $\mathrm{LDO}_{\mathrm{T}} \mathrm{TiO}_{2}$. (b) TG curves of $\mathrm{ZnAl}-\mathrm{LDH}$ and $\mathrm{LDH} @ \mathrm{TiO}_{2}$. (c) XRD patterns of $\mathrm{LDO} @ \mathrm{TiO}_{2}-T$ samples.

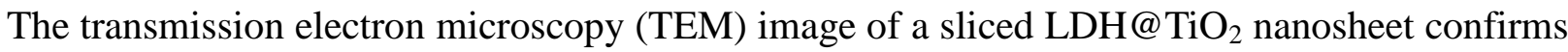
the core-shell structure. $\mathrm{TiO}_{2}$ shell layer was uniformly coated on the $\mathrm{LDH}$ core nanosheet, and the thickness of $\mathrm{ZnAl}-\mathrm{LDH}$ core and $\mathrm{TiO}_{2}$ shell is $\sim 300$ and $\sim 80 \mathrm{~nm}$, respectively (Figure 3a). No lattice

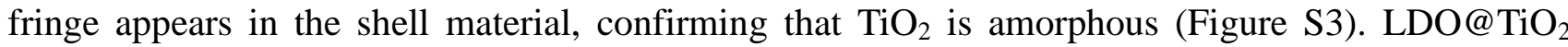
displays similar core-shell structure of $\mathrm{LDH}_{0} \mathrm{TiO}_{2}$ (Figure 3b). Porous structure can be observed in core and shell region, deriving from the release of gaseous species $\left(\mathrm{H}_{2} \mathrm{O}, \mathrm{CO}_{2}\right.$ etc. $)$ during the calcination process of ZnAl-LDH [41]. The corresponding energy dispersive X-ray spectrometry (EDS) mapping verify the well-defined $\mathrm{ZnAl}$ oxides core and $\mathrm{Ti}$ oxide shell structure: the $\mathrm{Zn}$ and $\mathrm{Al}$ elements show a high density in the core region while Ti element is located in the shell region (Figure 3c). The high-resolution transmission electron microscopy (HRTEM) image of LDO@ $\mathrm{TiO}_{2}$ reveals that $\mathrm{ZnAl}-\mathrm{LDH}$ core and amorphous $\mathrm{TiO}_{2}$ shell of $\mathrm{LDH}_{0} \mathrm{TiO}_{2}$ have convert to $\mathrm{ZnAl}-\mathrm{LDO}$ and anatase $\mathrm{TiO}_{2}$ phases (Figure 3d). In shell region, the interplanar distance of $0.352 \mathrm{~nm}$ corresponds to the (101) plane of anatase $\mathrm{TiO}_{2}$ [42]. The interplanar distances of $0.248 \mathrm{~nm}, 0.260 \mathrm{~nm}$ and $0.281 \mathrm{~nm}$ in core region can be ascribed to the (100), (002), and (101) planes of zincite $\mathrm{ZnO}$, 
respectively [43]. The surface area and pore size distribution of prepared samples were investigated by $\mathrm{N}_{2}$-adsorption/desorption measurements. The type-IV isotherm with H3-type hysteresis loops

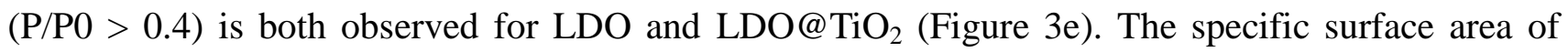
$\mathrm{ZnAl-LDH}$ is relatively low $\left(7.9 \mathrm{~m}^{2} \mathrm{~g}^{-1}\right) . \mathrm{ZnAl}-\mathrm{LDO}$ has an enhanced specific surface area $\left(43.8 \mathrm{~m}^{2}\right.$ $\mathrm{g}^{-1}$ ), and $\mathrm{LDO} @ \mathrm{TiO}_{2}$ further increases to $73.8 \mathrm{~m}^{2} \mathrm{~g}^{-1}$. ZnAl-LDO presents mesoporous distribution with the main pore size of $8-9 \mathrm{~nm}$ (Figure 3f). For $\mathrm{LDO} @ \mathrm{TiO}_{2}$, the pore sizes distribute with two peaks (4-5 and 8-9 $\mathrm{nm}$ ). It can be inferred from the TEM images that the 4-5 and 8-9 $\mathrm{nm}$ mesoporous of $\mathrm{LDO} @ \mathrm{TiO}_{2}$ mainly corresponds to the porous $\mathrm{TiO}_{2}$ shell and $\mathrm{ZnAl}-\mathrm{LDO}$ core,

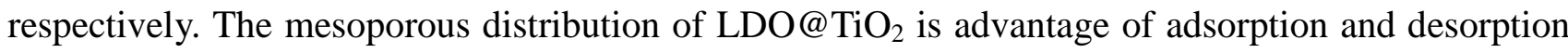
of dyes.
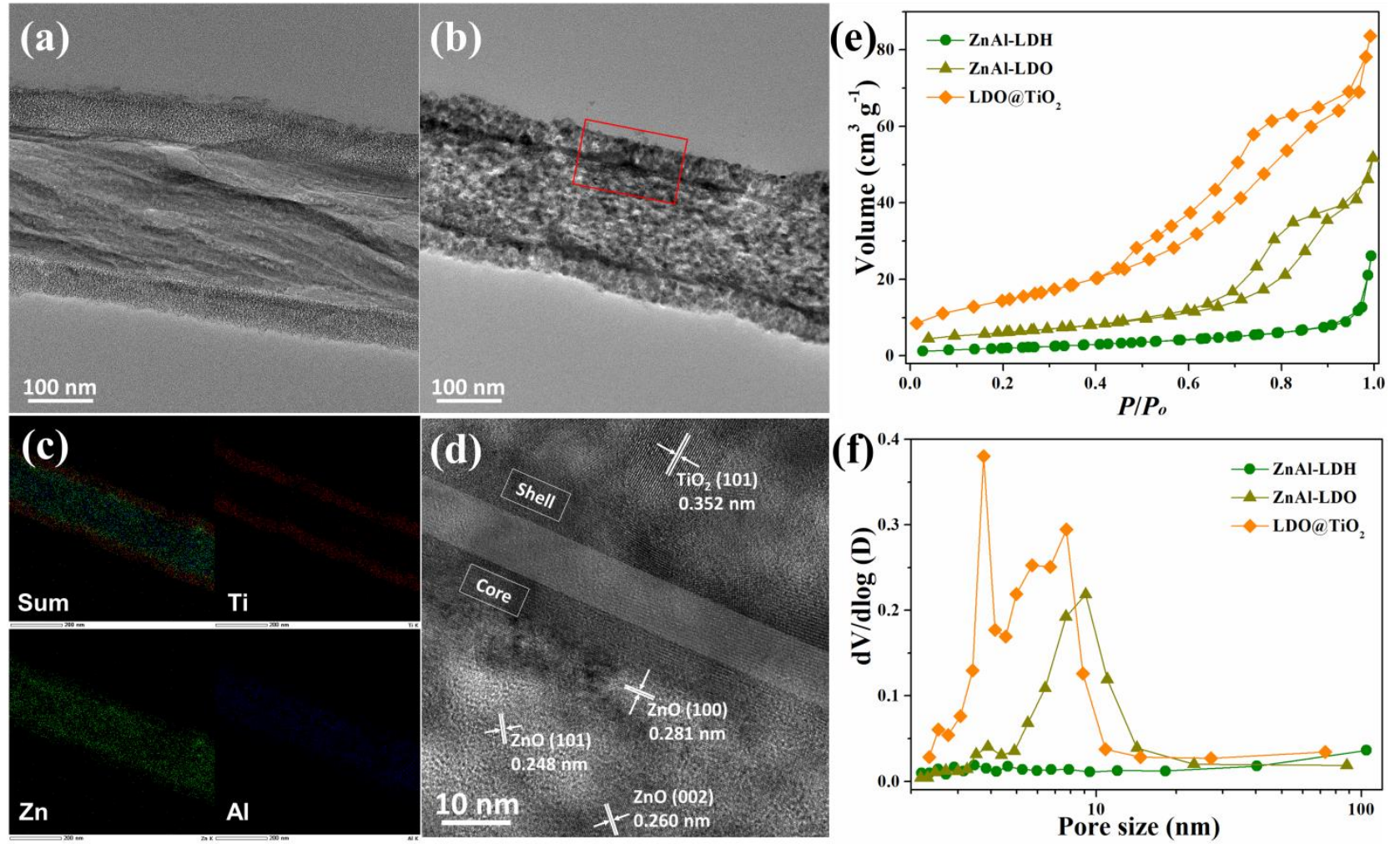

Figure 3. TEM images of (a) $\mathrm{LDH} @ \mathrm{TiO}_{2}$ and (b) $\mathrm{LDO} @ \mathrm{TiO}_{2}$. (c) EDS mapping and (d) HRTEM image of $\mathrm{LDH} @ \mathrm{TiO}_{2}$. (e) $\mathrm{N}_{2}$-sorption isotherms and (f) pore-size distribution of ZnAl-LDH, ZnAl-LDO and $\mathrm{LDO} @ \mathrm{TiO}_{2}$, respectively.

Furthermore, it is found that the growth of $\mathrm{TiO}_{2}$ shell on $\mathrm{ZnAl}-\mathrm{LDH}$ can be controlled by the concentration of $\mathrm{Ti}(\mathrm{OBu})_{4}$ in the hydrothermal solution (see details in the experimental section). The 
SEM images of two samples obtained in low and high concentrations of $\operatorname{Ti}(\mathrm{OBu})_{4}$ (denoted as LDH@ $\left.\mathrm{TiO}_{2}-\mathrm{L}, \mathrm{LDH} @ \mathrm{TiO}_{2}-\mathrm{H}\right)$ are show in Figure 4a and 4b, respectively. The thickness of LDH@ $\mathrm{TiO}_{2}-\mathrm{L}$ nanosheet is much thinner than that of $\mathrm{LDH}_{0} \mathrm{TiO}_{2}$, suggesting that small amount of $\mathrm{TiO}_{2}$ was coated in the $\mathrm{ZnAl}-\mathrm{LDH}$. LDH@ $\mathrm{TiO}_{2}-\mathrm{H}$ nanosheet displays thick $\mathrm{TiO}_{2}$ shell, and some $\mathrm{TiO}_{2}$ microspheres can be observed outside the core-shell materials (Figure S4). These experimental results demonstrate that $\mathrm{LDH}_{0} \mathrm{TiO}_{2}$ fabricated in a middle concentration of $\mathrm{Ti}(\mathrm{OBu})_{4}$ can be considered as an optimal sample in this work. Based on the hydrolysis mechanism of $\mathrm{Ti}(\mathrm{OBu})_{4}$, the in-situ growth process of $\mathrm{TiO}_{2}$ on $\mathrm{ZnAl-LDH}$ was schematically shown in Figure 4c. The $-\mathrm{OH}$ group and absorbed water molecules in $\mathrm{LDH}$ surface provide polar reaction environment, so the dealcoholization of $\mathrm{Ti}(\mathrm{OBu})_{4}$ preferentially react on the surface of $\mathrm{ZnAl}-\mathrm{LDH}$. The intermediate $\mathrm{Ti}(\mathrm{OH})_{4}$ keeps the going of hydrolysis process [44]. The hydrolysis process gradually reaches equilibrium as the consumption of $\mathrm{Ti}(\mathrm{OBu})_{4}$. Finally, amorphous $\mathrm{TiO}_{2}$ was in-situ grow on the surface of LDHs nanosheets to form core-shell structure.
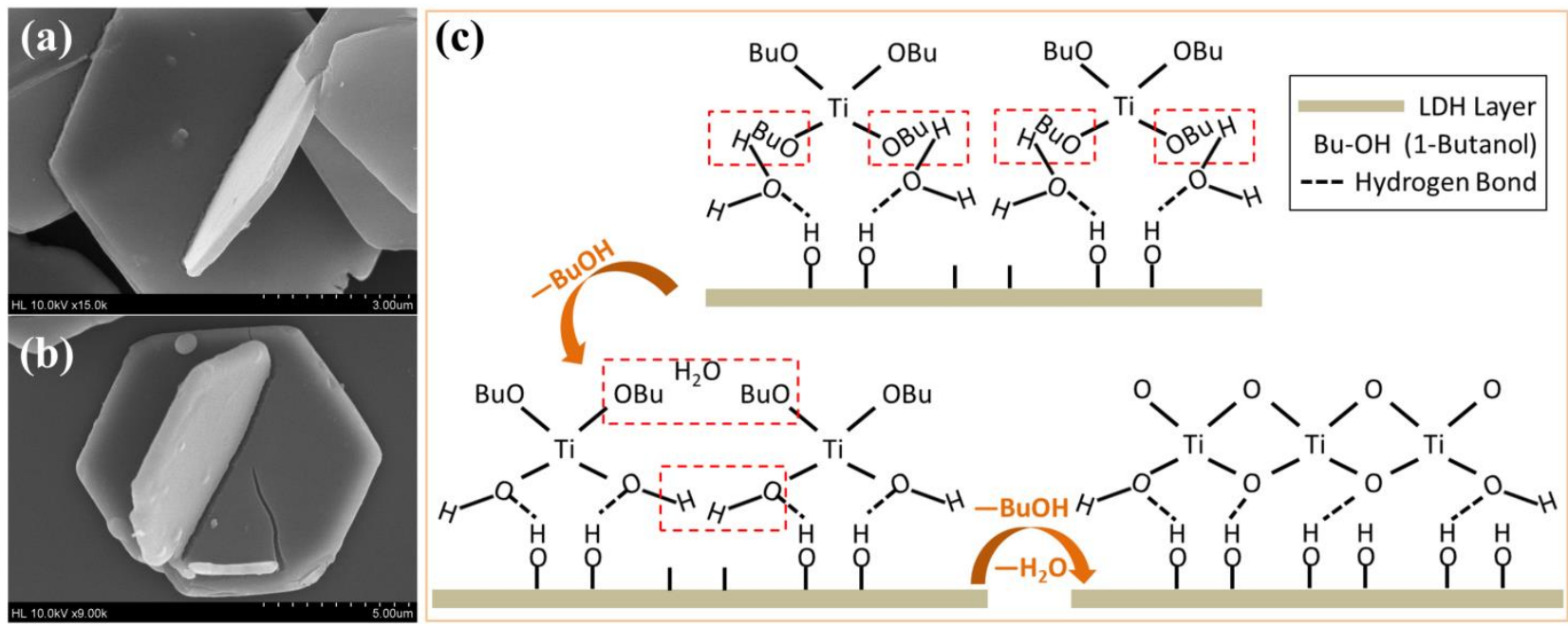

Figure 4. SEM images of (a) $\mathrm{LDH} @ \mathrm{TiO}_{2}-\mathrm{L}$ and (b) $\mathrm{LDH} @ \mathrm{TiO}_{2}-\mathrm{L}$. (c) the proposed pathways for the in-situ growth process of $\mathrm{TiO}_{2}$ on the $\mathrm{ZnAl}-\mathrm{LDH}$ surface.

\subsection{Photocatalytic degradation performance}

The photocatalytic degradation performance of organic pollutions was evaluated by degradation of methylene blue (MB, a typical cationic dye) and acid orange ( $\mathrm{AO}$, a typical anion dye) in neutral 
aqueous solution (Commercial P25 was used as a control photocatalyst). The concentration of MB or AO was analyzed by measuring the absorbance at maximum wavelength of $664 \mathrm{~nm}$ or $484 \mathrm{~nm}$ using a UV-vis spectrophotometer, respectively (Figure S5 and S6). The absorption properties of MB and AO for $\mathrm{LDO} @ \mathrm{TiO}_{2}, \mathrm{ZnAl}-\mathrm{LDO}$ and $\mathrm{P} 25 \mathrm{TiO}_{2}$ photocatalysts were distinctly different (Figure 6a). The adsorption efficiency of $\mathrm{MB}$ and $\mathrm{AO}$ for P25 were both relatively low. $\mathrm{LDO}_{0} \mathrm{TiO}_{2}$ and ZnAl-LDO display $10.9 \%$ and $9.1 \%$ adsorption efficiency of MB, which is similar with P25. But for the anionic $\mathrm{AO}$, the adsorption efficiency of $\mathrm{LDO} @ \mathrm{TiO}_{2}$ and $\mathrm{ZnAl}-\mathrm{LDO}$ dramatically increased to $51.2 \%$ and $70.8 \%$, respectively. The high adsorption efficiencies can be attributed to the regeneration of $\mathrm{ZnAl}-\mathrm{LDH}$ which bringing with the chemical adsorption of anionic $\mathrm{AO}$. It was reported that LDOs can convert to LDHs due to the "memory effect" when it contacts with water solutions containing with anions [45]. The (003), (006) reflections at $12.2^{\circ}, 24.3^{\circ}$ appears in the XRD patterns of used $\mathrm{LDO} @ \mathrm{TiO}_{2}$ and $\mathrm{ZnAl}-\mathrm{LDO}$, demonstrating the regeneration of ZnAl-LDH (Figure S7). The reservation of the reflections of $\mathrm{ZnO}$ indicates that only a part of ZnAl-LDO convert to ZnAl-LDH. To eliminate the effect of dyes adsorption, the used photocatalysts were mixed with dye solutions for $40 \mathrm{~min}$ to reach the adsorption-desorption equilibrium before the irradiation reaction.

Under irradiation reaction, the MB photodegradation efficiency of ZnAl-LDO is $41.7 \%$ within 120 min, which is lower than that of P25 (Figure 5b). This result indicates that pristine ZnAl-LDO is a bad photocatalyst. $\mathrm{LDO} @ \mathrm{TiO}_{2}$ displays much enhanced degradation efficiency $(86.4 \%)$, deriving from the synergy of $\mathrm{ZnAl-LDO}$ core and $\mathrm{TiO}_{2}$ shell. For the anionic $\mathrm{AO}$, the degradation efficiencies

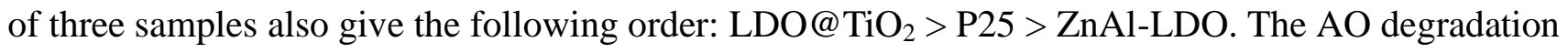
efficiencies of three samples are higher than that of $\mathrm{MB}$, indicating that the adsorption of dyes on surface of photocatalysts facilitates to the degradation process. Furthermore, the total organic carbon (TOC) analysis was measured to determine the mineralization efficiencies of dyes by the photocatalytic degradation reaction (Figure 5c). The TOC removal efficiency of ZnAl-LDO is 
inferior to $\mathrm{P} 25$, which is only $24.8 \%(\mathrm{MB})$ and $28.8 \%(\mathrm{AO})$ in $120 \mathrm{~min}$. The TOC removal

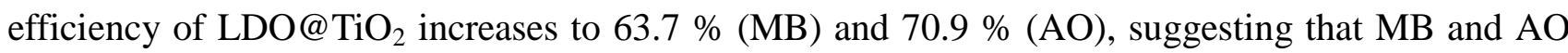
can be mostly mineralized to $\mathrm{H}_{2} \mathrm{O}$ and $\mathrm{CO}_{2}$ by the photocatalytic process of $\mathrm{LDO} @ \mathrm{TiO}_{2}$. In addition, the stability of the $\mathrm{LDO} @ \mathrm{TiO}_{2}$ was carried out by a cycle photocatalytic degradation reaction of $\mathrm{MB}$ and AO. It exhibits nearly constant photodegradation performance after three cycles, indicating the

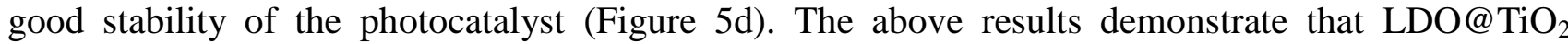
core-shell material is an excellent photocatalysis for photodegradation of organic pollutions.
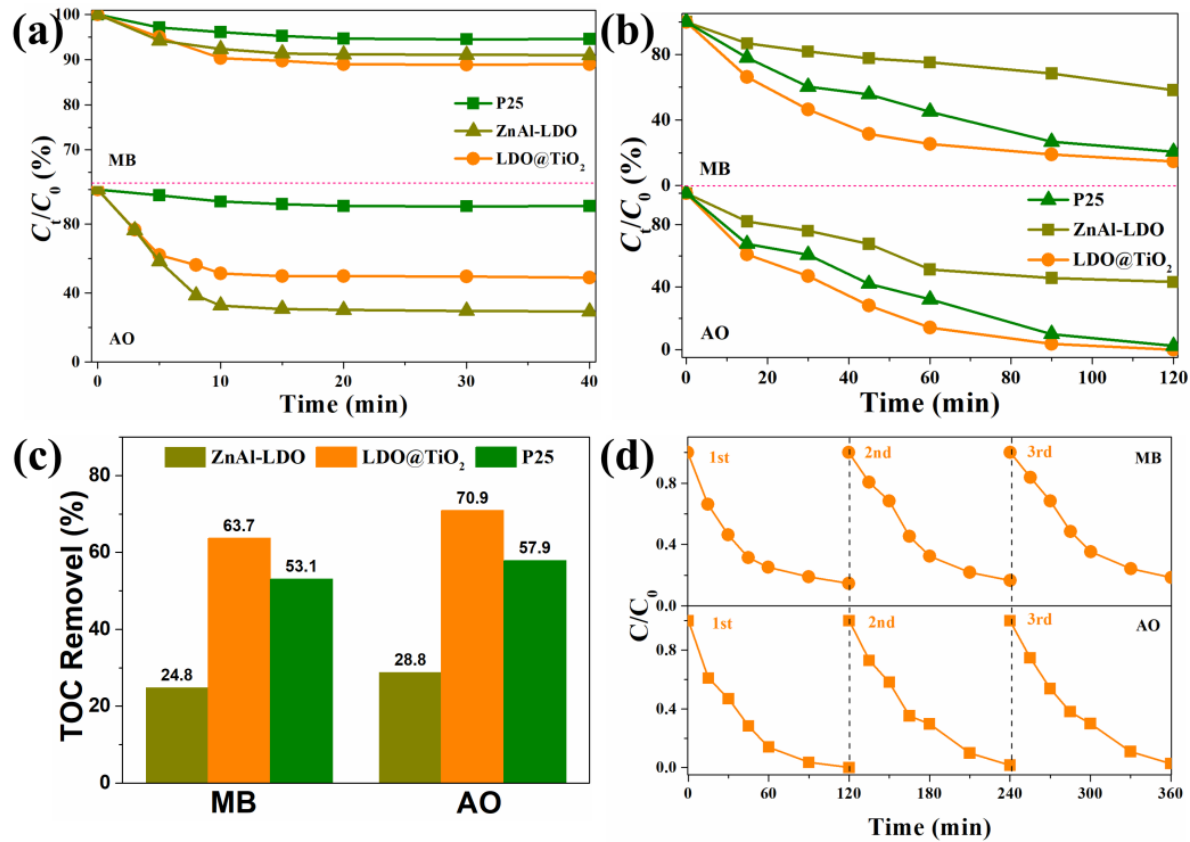

Figure 5. (a) Absorption efficiency, (b) photodegradation efficiency and (c) TOC removal efficiency of MB and $\mathrm{AO}$ for $\mathrm{ZnAl}-\mathrm{LDO}, \mathrm{LDO} @ \mathrm{TiO}_{2}$ and $\mathrm{P} 25$, respectively. (d) cycle experiments of $\mathrm{LDO} @ \mathrm{TiO}_{2}$ for $\mathrm{MB}$ and $\mathrm{AO}$ photocatalytic degradation reaction.

\subsection{Mechanism discussion}

Further investigated were carried out to give a deep insight into the enhanced photocatalytic degradation performance of $\mathrm{LDO} @ \mathrm{TiO}_{2}$. The elemental valence state of $\mathrm{LDO} @ \mathrm{TiO}_{2}, \mathrm{ZnAl}-\mathrm{LDO}$ and commercial anatase $\mathrm{TiO}_{2}\left(\mathrm{TiO}_{2}\right.$-Anatase $)$ were studied by $\mathrm{X}$-ray photoelectron spectroscopy (XPS). The full spectrum of $\mathrm{LDO} @ \mathrm{TiO}_{2}$ reveals signals of $\mathrm{Zn}, \mathrm{Al}, \mathrm{Ti}$ and $\mathrm{O}$ element (Figure $\mathrm{S} 8$ ). As shown in Figure 6a, O 1s XPS spectrum can be deconvoluted into two peaks at $530.0 \mathrm{eV}$ and 531.7 
$\mathrm{eV}$, which is assigned to the lattice oxygen $\mathrm{O}^{2-}$ and surface $-\mathrm{OH}$ group, respectively. The surface $\mathrm{OH}$ group is considered as one of the main defects in metal oxides [46]. Strong - OH peak is observed in $\mathrm{ZnAl}-\mathrm{LDO}$, which is consistent with the reports that LDO materials are hydrophilic on

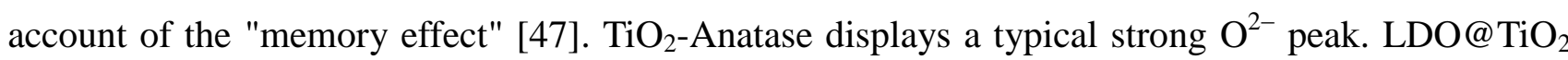
present the weakest $-\mathrm{OH}$ group peak and the strongest $\mathrm{O}^{2-}$ peak, suggesting that the surface defect of LDO and $\mathrm{TiO}_{2}$ are suppressive due to the synergy of core and shell components. Two dominant peaks at 1022.6 and $1045.7 \mathrm{eV}$ corresponding to $\mathrm{Zn} 2 \mathrm{p}_{3 / 2}$ and $2 \mathrm{p}_{1 / 2}$ are observed in ZnAl-LDO (Figure 6b). The binding energies of $\mathrm{Zn}^{2+}$ status is close to $\mathrm{Zn}-\mathrm{OH}$ than $\mathrm{Zn}-\mathrm{O}$, which is consistent with the O 1s XPS spectrum. After the incorporation of $\mathrm{TiO}_{2}$ shell, two peaks of $\mathrm{Zn} 2 \mathrm{p}$ decrease to 1021.7 and $1044.8 \mathrm{eV}$, indicating the increase of $\mathrm{Zn}-\mathrm{O}$ and decrease of $\mathrm{Zn}-\mathrm{OH}$ bond in $\mathrm{LDO} @ \mathrm{TiO}_{2}$. $\mathrm{TiO}_{2}$-Anatase shows the binding energies of 458.6 and $464.3 \mathrm{eV}$ for $\mathrm{Ti} 2 \mathrm{p}_{3 / 2}$ and $\mathrm{Ti} 2 \mathrm{p}_{1 / 2}$, respectively. A negative shift $(0.5 \mathrm{eV})$ of $\mathrm{Ti} 2 \mathrm{p}$ peaks is observed in $\mathrm{LDO}_{0} \mathrm{TiO}_{2}$, indicating a distinct increase in the electron density of Ti (Figure 6c). This remarkable negative shift suggests the electron transfer from ZnAl-LDO to $\mathrm{TiO}_{2}$ group in $\mathrm{LDO} @ \mathrm{TiO}_{2}$.

In addition, the bandgap of $\mathrm{ZnAl}-\mathrm{LDO}$ and $\mathrm{LDO} @ \mathrm{TiO}_{2}$ were estimated by the UV-vis absorption spectra (Figure 6d). ZnAl-LDO exhibit light absorption edge at $420 \mathrm{~nm}$, corresponding to the band gap of $3.0 \mathrm{eV}$. The absorption edge of $\mathrm{LDO} @ \mathrm{TiO}_{2}$ and $\mathrm{TiO}_{2}$-Anatase are both located at $\sim 390 \mathrm{~nm}$, confirming the successful formation of anatase $\mathrm{TiO}_{2}$ in the core-shell photocatalyst. The electron paramagnetic resonance (EPR) measurements of $\mathrm{LDO} @ \mathrm{TiO}_{2}$ and $\mathrm{ZnAl-LDO}$ were shown in Figure 6e. Under light irradiation, DMPO-·OH (peak intensity ratio = $1: 2: 2: 1$ ) signals are

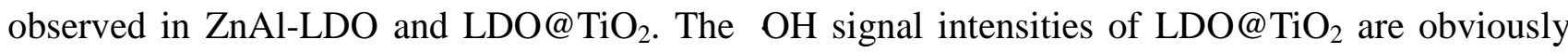
higher than that of $\mathrm{ZnAl}-\mathrm{LDO}$ under same irradiation time. Since the $\cdot \mathrm{OH}$ are derived from isolated photogenerated holes, the improved signal intensities of $\mathrm{LDO} @ \mathrm{TiO}_{2}$ indicates a higher separation efficiency for the photo-generated electron-hole pairs [48]. Photoelectrochemical experiments under on-off cyclical light were further performed to probe the interface charge transfer behaviors (Figure 
6f). ZnAl-LDO displays a relatively low photocurrent response. The photocurrent density of LDO@ $\mathrm{TiO}_{2}$ has a remarkable improvement, suggesting the lower recombination of photo-generated carriers.
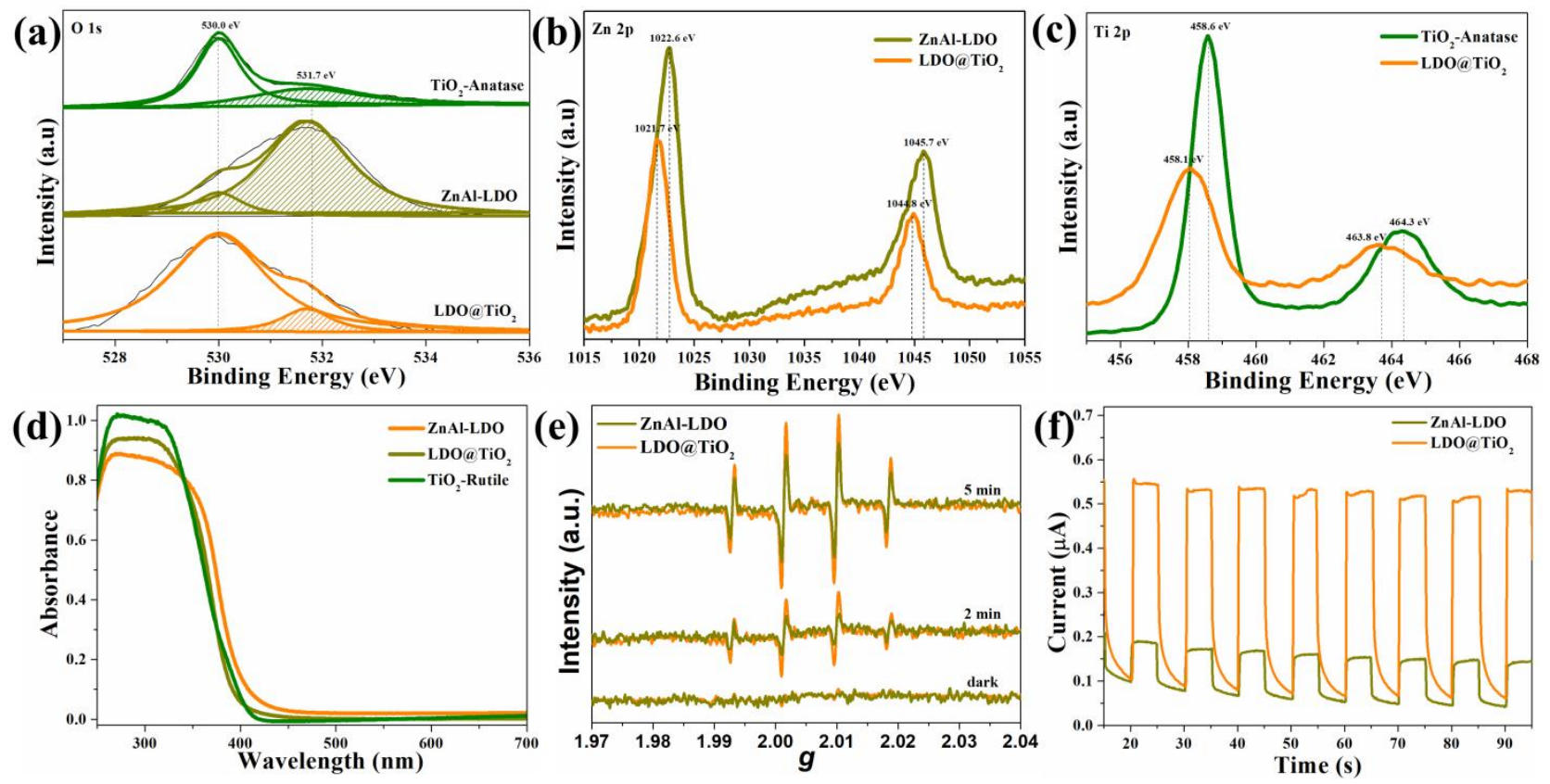

Figure 6. (a) $\mathrm{O} 1 \mathrm{~s}$ XPS of $\mathrm{TiO}_{2}, \mathrm{ZnAl}-\mathrm{LDO}$ and $\mathrm{LDO}_{\mathrm{T}} \mathrm{TiO}_{2}$, respectively. (b) $\mathrm{Zn} 2 \mathrm{p}$ XPS of $\mathrm{ZnAl}-\mathrm{LDO}$ and LDO@ $\mathrm{TiO}_{2}$. (c) Ti 2p XPS of $\mathrm{TiO}_{2}$ and $\mathrm{LDO} @ \mathrm{TiO}_{2}$. (d) UV-vis diffuse reflectance spectra of ZnAl-LDO, LDO@ $\mathrm{TiO}_{2}$ and $\mathrm{TiO}_{2}$-Anatase, respectively. (e) EPR spectra and (f) photocurrents of $\mathrm{ZnAl}-\mathrm{LDO}$ and $\mathrm{LDO} @ \mathrm{TiO}_{2}$, respectively.

Given the results above, a mechanism for the enhanced photocatalytic degradation performance

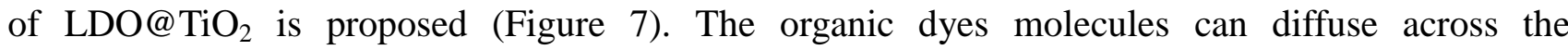
mesoporous $\mathrm{TiO}_{2}$ shell to interior $\mathrm{ZnAl}$-LDO. The high specific surface of $\mathrm{LDO} @ \mathrm{TiO}_{2}$ provides sufficient reactive sites. Under illumination, electron-hole pairs would generate both in ZnAl-LDO and $\mathrm{TiO}_{2}$. Due to the band energy difference of $\mathrm{ZnAl}-\mathrm{LDO}$ and $\mathrm{TiO}_{2}[49,50]$, the photogenerated holes on the valence band of $\mathrm{TiO}_{2}$ tend to migrate to $\mathrm{ZnAl}-\mathrm{LDO}$ while the photogenerated electrons of $\mathrm{ZnAl}-\mathrm{LDO}$ travel to $\mathrm{TiO}_{2}$. The opposite migration in the $\mathrm{ZnAl}-\mathrm{LDO} / \mathrm{TiO}_{2}$ heterojunction interface hinders the recombination of charge carriers, which has been confirmed by the EPR and photoelectrochemical experiment results. The generation of $\cdot \mathrm{OH}$ on the surface of $\mathrm{TiO}_{2}$ and ZnAl-LDO can efficiently decompose organic dyes molecules to low molecules $\left(\mathrm{CO}_{2}\right.$ etc. $)$. The 
mesoporous structure of nanosheets facilitates the diffusion of reactants and products. Therefore, LDO@ $\mathrm{TiO}_{2}$ core-shell nanosheets exhibit excellent photocatalytic degradation performances.

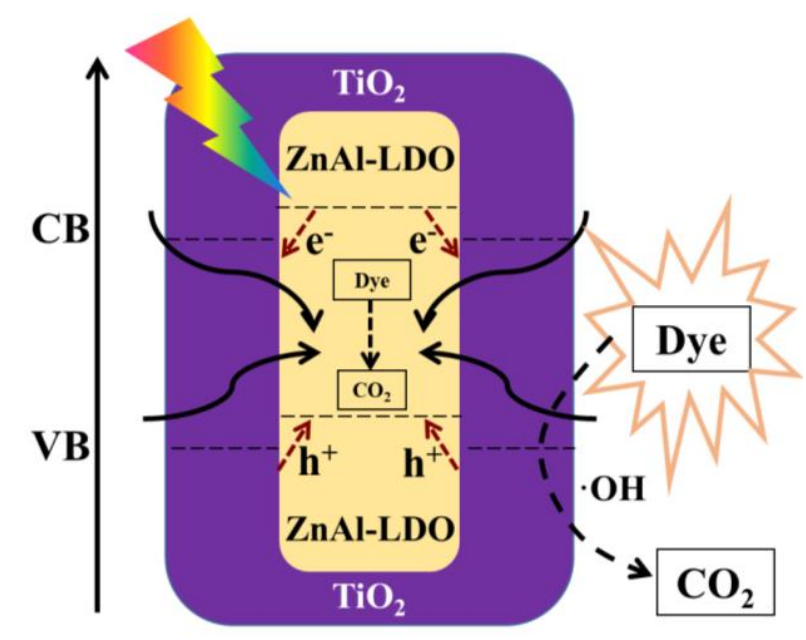

Figure 7. A schematic illustration for the photodegradation process of $\mathrm{LDO} @ \mathrm{TiO}_{2}$ core-shell nanosheets.

\section{Conclusions}

In conclusion, $\mathrm{LDO} @ \mathrm{TiO}_{2}$ core-shell nanosheets photocatalyst were designed and successfully prepared by the transformation of $\mathrm{LDH} @ \mathrm{TiO}_{2}$ precursor. The fabrication process of $\mathrm{TiO}_{2}$ shell and LDOs core can be facilely controlled by the concentration of $\mathrm{Ti}(\mathrm{OBu})_{4}$ and LDHs processors. The prepared $\mathrm{LDO} @ \mathrm{TiO}_{2}$ photocatalyst gives typical core-shell nanosheets morphology with mesoporous structure and high specific surface area. TEM, XPS and photoelectrochemical analyses demonstrate the successful fabrication of $\mathrm{ZnAl}-\mathrm{LDO} / \mathrm{TiO}_{2}$ core-shell heterojunction, which facilitate the charge separation efficiency. Consequently, $\mathrm{LDO} @ \mathrm{TiO}_{2}$ photocatalysts exhibits superior

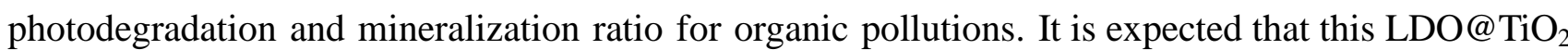
fabrication strategy can be applicable to preparation of other core-shell metal oxide composite materials.

\section{Acknowledgements}

This work was supported by the Natural Science Foundation of Hebei Province (B2020205006, B2021205027), the National Natural Science Foundation of China (21902042, 21871076), and the Science Foundation of Hebei Normal University (L2019B14). 


\section{Reference}

[1] Sofian, K.; Matthew, A. M.; Robert, B. A.; Howard, H. P. Recent advances on $\mathrm{TiO}_{2}$-based photocatalysts toward the degradation of pesticides and major organic pollutants from water bodies. Catal. Rev. 2019, 62, 1-65.

[2] Huang, X. P.; Chen, Y.; Eric, W.; Zong, M. R.; Wang, Y.; Zhang, X.; Odeta, Q.; Wang, Z. M.; Kevin, M. R. Facet-Specific Photocatalytic Degradation of Organics by Heterogeneous Fenton Chemistry on Hematite Nanoparticles. Environ. Sci. Technol. 2019, 53, 10197-10207.

[3] Hassan, A.; Asad. M.; Jechan, L.; Ki-H, K.; Jae-W, P.; Alex, C. K. Y. Photocatalysts for degradation of dyes in industrial effluents: Opportunities and challenges. Nano Res. 2020, 12, 9462-9470.

[4] Wang, Y. T.; Zhu, C. Z.; Zuo, G.C; Guo, Y.; Xiao, W.; Dai, Y. X.; Kong, J. J.; Xu, X. M.; Zhou, Y. X.; Xie, A.; Sun, C.; Xian, Q. M. 0D/2D $\mathrm{Co}_{3} \mathrm{O}_{4} / \mathrm{TiO}_{2}$ Z-Scheme heterojunction for boosted photocatalytic degradation and mechanism investigation. Appl. Catal. B 2020, 278, 119298.

[5] Wan, D.; Wang, J.; Dionysios, D. D.; Kong,Y. Q.; Yao,W. Y.; Steplinpaulselvin S, Chen,Y. Photogeneration of Reactive Species from Biochar-Derived Dissolved Black Carbon for the Degradation of Amine and Phenolic Pollutants. Environ. Sci. Technol. 2021, 55, 8866-8876.

[6] Monteagudo, J. M.; Durán, A.; Martín, I. S.; Carrillo, P. Effect of sodium persulfate as electron acceptor on antipyrine degradation by solar $\mathrm{TiO}_{2}$ or $\mathrm{TiO}_{2} / \mathrm{rGO}$ photocatalysis. Chem. Eng. J. 2019, $364,257-268$.

[7] Zhang, R. B.; Du, B.; Li, Q. C; Cao, Z. Q.; Feng, G.; Wang, X. W. $\alpha-\mathrm{Fe}_{2} \mathrm{O}_{3}$ nanoclusters confined into UiO-66 for efficient visible-light photodegradation performance. Appl. Surf. Sci. 2019, 466, 956-963. 
[8] Zhu, W. Y.; Liu, J. C.; Yu, S. Y.; Zhou, Y.; Yan, X. L. Ag loaded $\mathrm{WO}_{3}$ nanoplates for efficient photocatalytic degradation of sulfanilamide and their bactericidal effect under visible light irradiation. J. Hazard. Mater. 2016, 318, 407-416.

[9] Liu, H. B.; Hou, H. L.; Gao, F. M.; Yao, X. H.; Yang, W.Y. Tailored Fabrication of BiVO Thoroughly Mesoporous Nanofibers and Their Visible-Light Photocatalytic Activities. ACS Appl. Mater. Interfaces 2016, 8, 1929-1936.

[10]Meng, A.Y.; Zhang, J.; Xu, D. F.; Cheng, B.; Yu, J.G. Enhanced photocatalytic $\mathrm{H}_{2}$-production activity of anatase $\mathrm{TiO}_{2}$ nanosheet by selectively depositing dual-cocatalysts on $\{101\}$ and $\{001\}$ facets. Appl. Catal. B 2016, 198, 286-294.

[11]Huang, X. Q.; Zhang, R. K.; Gao, X. R.; Yu, B. R.; Gao, Y. Z.; Han, Z. Z. TiO 2 -rutile/anatase homojunction with enhanced charge separation for photoelectrochemical water splitting. Int. J. Hydrog. Energy 2021, 46, 26358-26366.

[12]Wang, Q.; Huang, J.;Y.; Sun, H.; T.; Zhang, K.; Q.; Lai, Y.; K. Uniform carbon dots@ $\mathrm{TiO}_{2}$ nanotube arrays with full spectrum wavelength light activation for efficient dye degradation and overall water splitting. Nanoscale 2017, 9, 16046-16058.

[13]Wei, H.; McMaster, W. A.; Jeannie, Z. Y. T.; Chen, D. H.; Rachel, A. C. Tricomponent brookite/anatase $\mathrm{TiO}_{2} / g-\mathrm{C}_{3} \mathrm{~N}_{4}$ heterojunction in mesoporous hollow microspheres for enhanced visible-light photocatalysis. J. Mater. Chem. A 2018, 6, 7236-7245.

[14] Sadaf, B. K.; Hou, M. J. ; Shuang, S.; Zhang, Z. J. Morphological influence of $\mathrm{TiO}_{2}$ nanostructures (nanozigzag, nanohelics and nanorod) on photocatalytic degradation of organic dyes. Appl. Surf. Sci. 2017, 400, 184-193.

[15]Amarja, P. N.; Hemant, M.; Vijay, S. W.; Laxmi, S.; Abhijeet, R.; Saeed, M. A.; Ali, A. A.; 
Sheshanath, V. B. Pranay P Morajkar. Super porous $\mathrm{TiO}_{2}$ photocatalyst: Tailoring the agglomerate porosity into robust structural mesoporosity with enhanced surface area for efficient remediation of azo dye polluted waste water. J. Environ. Manage. 2020, 258, 110029.

[16]Kisung, L.; Hyewon, Yoon.; Changui, A.; Jun,Y. P.; Seokwoo, J. Strategies to improve the photocatalytic activity of $\mathrm{TiO}_{2}: 3 \mathrm{D}$ nanostructuring and heterostructuring with graphitic carbon nanomaterials. Nanoscale 2019, 11, 7025-7040.

[17]Chen, D. Y.; Zhu, H. G.; Yang, S.; Li, N.J.; Xu, Q. F.; Li, H.; He, J. H.; Lu, J. M. Micro-Nanocomposites in Environmental Management. Adv. Mater. 2016, 28, 10443-10458.

[18]Chen, Z.; Li, X. M.; Xu, Q. Z.; Tao, Z. L.T.; Yao, F. B.; Huang, X. D.; Wu, Y.; Wang, D. B.; Jiang, P. H.; Yang, Q. Three-dimensional network space $\mathrm{Ag}_{3} \mathrm{PO}_{4} / \mathrm{NP}-\mathrm{CQD} / \mathrm{rGH}$ for enhanced organic pollutant photodegradation: Synergetic photocatalysis activity/stability and effect of real water quality parameters. Chem. Eng. J. 2020, 390, 124454.

[19]Zong, M. R.; Song, D.; Zhang, X.; Huang, X. P.; Lu, X. C.; Kevin M. R. Facet-Dependent Photodegradation of Methylene Blue by Hematite Nanoplates in Visible Light. Environ. Sci. Technol. 2021, 55, 677-688.

[20]Guo, Y.; Wang, P. F.; Qian, J.; Ao, Y. H.; Wang, C.; Hou, J. Phosphate group grafted twinned $\mathrm{BiPO}_{4}$ with significantly enhanced photocatalytic activity: Synergistic effect of improved charge separation efficiency and redox ability. Appl. Catal. B 2018, 234, 90-99.

[21]Chen, P.; Lee, B.; Giovanni, C.; Huang, J.; Wang, B.; Wang,Y. J.; Deng, S. B.; Gang, Y. Degradation of Ofloxacin by Perylene Diimide Supramolecular Nanofiber Sunlight-Driven Photocatalysis. Environ. Sci. Technol. 2019, 53, 1564-1575.

[22]Chen, J.; Wang, M. G.; Han, J.; Guo, R. $\mathrm{TiO}_{2}$ nanosheet/NiO nanorod hierarchical nanostructures: 
p-n heterojunctions towards efficient photocatalysis. J. Colloid Interface Sci. 2020, 562, 313-321.

[23] Samuel, O. -B. O.; Francis, O.; Penny, P. G. Tuning the electronic and structural properties of Gd- $\mathrm{TiO}_{2}-\mathrm{GO}$ nanocomposites for enhancing photodegradation of IC dye: The role of $\mathrm{Gd}^{3+}$ ion. Appl. Catal. B 2019, 243, 106-120.

[24]Seyed, M. G.; Kugalur, S. R.; Hoomin, L.; Hong, I. J.; Somayeh, Z. N.; Young, K. H.; Yun, S. H. Hierarchical N-doped $\quad \mathrm{TiO}_{2} @ \mathrm{Bi}_{2} \mathrm{~W}_{\mathrm{x}} \mathrm{Mo}_{1-\mathrm{x}} \mathrm{O}_{6}$ core-shell nanofibers for boosting visible-light-driven photocatalytic and photoelectrochemical activities. J. Hazard. Mater. 2020, $391,122249$.

[25]Li, H.T.; Gao, Q. ; Wang, G. S.; Han, B.; Xia, K. S.; Zhou, C. G. Architecturing CoTiO 3 overlayer on nanosheets-assembled hierarchical $\mathrm{TiO}_{2}$ nanospheres as a highly active and robust catalyst for peroxymonosulfate activation and metronidazole degradation. Chem. Eng. J. 2020, 392, 123819.

[26]Zhong, H.; Yang, C.; Fan, L. Z.; Fu, Z. H.; Yang, X.; Wang, X. C.; Wang, R. H. Dyadic promotion of photocatalytic aerobic oxidation via the Mott-Schottky effect enabled by nitrogen-doped carbon from imidazolium-based ionic polymers. Energy Environ. Sci. 2019, 12, 418-426.

[27]Wang, L.; Zhang, Y.; Chen, L.; Xu, H. X.; Xiong, Y. J. 2D Polymers as Emerging Materials for Photocatalytic Overall Water Splitting. Adv. Mater. 2018, 30, 1801955.

[28]Lian, X. Y.; Xue, W. H.; Dong, S.; Liu, E. Z.; Li, H.; Xu, K. Z. Construction of S-scheme $\mathrm{Bi}_{2} \mathrm{WO}_{6} / \mathrm{g}-\mathrm{C}_{3} \mathrm{~N}_{4}$ heterostructure nanosheets with enhanced visible-light photocatalytic degradation for ammonium dinitramide. J. Hazard. Mater. 2021, 412, 125217.

[29]Willinton, Y. H.; Jeroen, L.; Pascal, V. D. V.; An, V. Recent advances on the utilization of layered double hydroxides (LDHs) and related heterogeneous catalysts in a lignocellulosic-feedstock biorefinery scheme. Green Chem. 2017, 19, 5269-5302. 
[30]Lu, Z. Y.; Qian, L.; Xu, W. W.; Tian, Y.; Jiang, M.; Li, Y. P.; Sun, X. M.; Duan, X. Dehydrated layered double hydroxides: Alcohothermal synthesis and oxygen evolution activity. Nano Res. 2016, 9, 3152-3161.

[31]Chen, X.; Wang, H. N.; Xia, B.; Meng, R. R. Noncovalent phosphorylation of CoCr layered double hydroxide nanosheets with improved electrocatalytic activity for the oxygen evolution reaction. Chem. Commun. 2019, 55, 12076-12079.

[32]Wu, C. C.; Li, H. Q.; Xia, Z. X.; Zhang, X. M.; Deng, R. Y.; Wang, S. L.; Sun, G. Q. NiFe Layered Double Hydroxides with Unsaturated Metal Sites via Pre-covered Surface Strategy for Oxygen Evolution Reaction. ACS Catal. 2020, 10, 11127-11135.

[33]Lin, Y. P.; Wang, H.; Peng, C. K.; Bu, L. M.; Chiang, C. L.; Tian, K.; Zhao, Y.; Zhao, J. Q.; Lin, Y. G.; Jong, M. L.; Gao, L. J. Co-Induced Electronic Optimization of Hierarchical NiFe LDH for Oxygen Evolution. Small 2020, 16, 2002426.

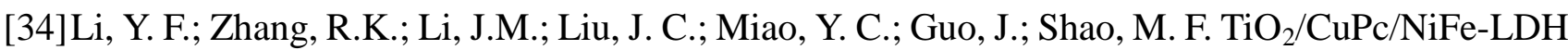
photoanode for efficient photoelectrochemical water splitting. Chin. Chem. Lett. 2021, 32, $1165-1168$.

[35]Peng, D.; Jing, Q. Y.; Feng, Z. J.; Niu, J. W.; Cheng, X.; Wu, X.; Zheng, X. X.; Yuan, X. Y. Facile preparation of AB-stacking graphene oxide/ZnAl-layered double hydroxide composites and enhanced visible-light photocatalytic performance of the calcined product. J. Phys. Chem. Solids 2020, 136, 109199.

[36]Zhao, Y. F.; Jia, X. D.; Chen, G. B.; Shang, L.; Geoffrey, I. N. W.; Wu, L. Z.; Tung, C. H.; Dermot O, H.; Zhang, T. R. Ultrafine NiO Nanosheets Stabilized by $\mathrm{TiO}_{2}$ from Monolayer NiTi-LDH Precursors: An Active Water Oxidation Electrocatalyst. J. Am. Chem. Soc. 2016, 138, 6517-6524. 
[37]Cai, Y. J.; Song, H. Y.; An, Z.; Xiang, X.; Shu, X.; He, J. The confined space electron transfer in phosphotungstate intercalated ZnAl-LDHs enhances its photocatalytic performance for oxidation/extraction desulfurization of model oil in air. Green Chem. 2018, 20, 5509-5519.

[38]Xu, Q.-H.; Xu, D.-M.; Guan, M.-Y.; Guo, Y. ; Qi, Q.; Li, G.-D. $\mathrm{ZnO} / \mathrm{Al}_{2} \mathrm{O}_{3} / \mathrm{CeO}_{2}$ composite with enhanced gas sensing performance. Sens. Actuators B Chem. 2013, 177, 1134-1141.

[39]Meng, Q. T.; Yan, H. Theoretical study on the topotactic transformation and memory effect of M (II) M (III)-layered double hydroxides. Mol. Simulat 2017, 43, 1338-1347.

[40]Rohini, S.; Suman, D. Synthesis and characterization of solar photoactive $\mathrm{TiO}_{2}$ nanoparticles with enhanced structural and optical properties. Adv Powder Technol 2018, 29, 211-219.

[41] Yuan, X. Y.; Jing, Q. Y.; Chen, J. T.; Li, L. Photocatalytic Cr(VI) reduction by mixed metal oxide derived from ZnAl layered double hydroxide. Appl Clay Sci 2017, 143, 168-174.

[42]Jeong-A, P.; Boram, Y.; Joongki, L.; In, G. K.; Jae,-H. K.; Jae,-W. C.; Hee,-D. P.; In, W. N.; Sang,-H. L. Ultrasonic spray pyrolysis synthesis of reduced graphene oxide/anatase $\mathrm{TiO}_{2}$ composite and its application in the photocatalytic degradation of methylene blue in water. Chemosphere 2018, 191, 738-746.

[43]Liu, Y. j.; Huang, D.; Liu, H. X.; Li, T. D.; Wang, J. G. ZnO tetrakaidecahedrons with co-exposed $\{001\},\{101\}$, and $\{100\}$ facets: shape-selective synthesis and enhancing photocatalytic performance. Cryst. Growth Des. 2019, 19, 2758-2764.

[44]Zhang, J.; Sun, P.; Jiang, P.; Guo, Z. Y.; Liu, W. X.; Lu, Q. P.; Cao, W. B. The formation mechanism of $\mathrm{TiO}_{2}$ polymorphs under hydrothermal conditions based on the structural evolution of $\left[\mathrm{Ti}(\mathrm{OH})_{\mathrm{h}}\left(\mathrm{H}_{2} \mathrm{O}\right)_{6-\mathrm{h}}\right]^{4-\mathrm{h}}$ monomers. J. Mater. Chem. C 2019, 7, 5764-5771.

[45]Zong, Y. T.; Li, K.T.; Tian, R.; Lin,Y. J.; Lu, C. Highly dispersed layered double oxide hollow 
spheres with sufficient active sites for adsorption of methyl blue. Nanoscale 2018, 10, $23191-23197$.

[46]Miao, J.; Zhao, X. J.; Zhang, Y.-X.; Lei, Z.-L.; Liu, Z.-H. Preparation of hollow hierarchical porous CoMgAl-borate LDH ball-flower and its calcinated product with extraordinary adsorption capacity for Congo red and methyl orange. Appl. Clay Sci. 2021, 207, 106093.

[47]Li, M. Z.; Wu, G. H.; Liu, Z. H.; Xi, X. Y.; Xia, Y.; Ning, J.; Yang, D.; Dong, A. G. Uniformly coating ZnAl layered double oxide nanosheets with ultra-thin carbon by ligand and phase transformation for enhanced adsorption of anionic pollutants. J. Hazard. Mater. 2020, 397, 122766.

[48]Wu, Y.; Wang, H.; Sun, Y. M.; Xiao, T.; Tu, W. G.; Yuan, X. Z.; Zeng, G. M.; Li, S. J.; Chew, J. W. Photogenerated charge transfer via interfacial internal electric field for significantly improved photocatalysis in direct Z-scheme oxygen-doped carbon nitrogen/CoAl-layered double hydroxide heterojunction. Appl. Catal. B 2018, 227, 530-540.

[49]Wu, M. M.; Chang, B. W.; Teik,-T. Lim.; Wen,-D. O.; Lei, J. X.; Mi, J. High-sulfur capacity and regenerable Zn-based sorbents derived from layered double hydroxide for hot coal gas desulfurization. J. Hazard. Mater. 2018, 360, 391-401.

[50]Sun, C. Y.; Xu, Q. H.; Xie, Y.; Ling, Y.; Hou, Y. Designed synthesis of anatase-TiO 2 (B) biphase nanowire/ZnO nanoparticle heterojunction for enhanced photocatalysis. J. Mater. Chem. A 2018, 6, 8289-8298. 